\title{
EL RUGIDO DE CALIBÁN: RUIDO, CULTURA Y SUBVERSIÓN EN TIEMPOS DE PRÓSPERO
}

\section{Jorge David García Castilla}

Universidad Nacional Autónoma de México, Facultad de Música

\section{Resumen}

El rugido de Calibán representa en este artículo el ruido que la modernidad ha tachado de incomprensible. Hablando específicamente del campo musical, este rugido está constituido por las prácticas sonoras que la cultura dominante trata de excluir. Con el fin de explorar distintos aspectos de la dominación capitalista y de los procesos de resistencia que se dan en su contra, este texto aborda tres ejes principales en los que las prácticas ruidistas se convierten en espacios de subversión de los valores culturales hegemónicos. El primero de estos ejes es el mercado, el segundo el cuerpo y el tercero el deseo. De manera transversal, exploraremos la relación que tiene el ruido con los procesos de descontrol social y de transformación identitaria.

\section{Palabras clave: RUIDO; SUBVERSIÓN; TRANSFORMACIÓN CULTURAL; ARTE EXPERIMENTAL; DECOLONIALISMO}

\section{THE ROAR OF CALIBAN: NOISE, CULTURE AND SUBVERSION IN TIMES OF PROSPERO}

\section{Abstract}

In this article, the roar of Caliban represents the noise that modernity has defined as incomprehensible. Speaking specifically of the musical field, we refer to sound practices that the dominant culture tries to exclude. In order to explore different aspects of capitalist domination and resistance processes, this text addresses three main areas in which noise practices become an act of subversion against hegemonic cultural values. The first of these axes is the market, the second is the body and the third is the desire. Transversely, we will explore the relationship between noise and uncontrolled processes of identity transformation.

Keywords: NOISE; SUBVERSION; CULTURAL TRANSFORMATION; EXPERIMENTAL ART; DECOLONIALISM

García Castilla, Jorge David. 2015. "El rugido de Calibán: ruido, cultura y subversión en tiempos de Próspero”. AusArt 3 (2): 251-260. D0I: 10.1387 /ausart. 15968

\section{AUSART}




\section{I}

No nos mirábamos. Cada quien entregado a su micrófono, se conectaba con el otro en una escucha que mezclaba el impacto de las bocinas con los diversos sonidos del recinto. Las texturas incisivas golpeaban por igual nuestras espaldas y nuestros dedos, mientras nuestras gargantas se estiraban convencidas de que toda aquella escena se desprendía de sus cuerdas sobreexcitadas. Gritábamos los dos y no había fuerza capaz de detenernos, y entre ruidos confusos el tiempo pasaba sin que fuéramos conscientes de ello.

En algún momento me detuve de imprevisto y él rugió con tal intensidad que disolvió la confusión dejándome apreciar, con sorprendente claridad, las disonancias que salían de su garganta: espectros guturales que surgían en el grito, destellos sobreagudos que resultaban del choque de la saliva con el micrófono, un feedback incisivo que amenazaba con tronar tanto bocinas como tímpanos. En aquel tumulto todo ruido parecía tener cabida, como si el grito fundara una extraña sociedad en la que todos los sonidos participaban. Era un pacto utópico, un mundo inverosímil en el que no existían reglas que limitaran el derecho de existir de cada gesto.

De repente, sin dar aviso, la saturación de estímulos cobró efectos alucinantes. Me vi entonces inmerso en alguna tragedia shakesperiana, sintiendo la tempestad que destruía lentamente nuestro barco. ¿Quién rugía en el escenario, a mi lado, al compás de mis propios rugidos? No el mago Próspero, sino el monstruo ruidoso Calibán: el deforme, el anormal, el esclavo del monarca que conquistara, a través de sus hechizos, las encantadas tierras de su naufragio.

\section{II}

En aquellos meses yo leía en El Parásito de Serres: "estamos rodeados por ruido (...). [E]l ruido nunca se detiene. Es nuestra apreciación del caos, nuestra aprehensión del desorden, nuestro único vínculo con la distribución dispersa de las cosas" (Serres 1982, 126). Mientras cruzaba la ciudad en el metro sobrepoblado, me repetía aquellas palabras tratando de entender su sentido secreto. Suponía que el desorden era parte constitutiva de nuestro estar en este mundo, y me preguntaba por qué nos entregamos con devoción a la 
estructura ordenante del cotidiano. A ratos, como jugando a no ser parte de mi entorno, declamaba las frases ruidosas de Serres, y cual parásito citadino contribuía a la dispersión con mi porción desordenada de ruido.

"El ruido alimenta un nuevo orden", continúa Serres, dejando claro que a pesar de que "destruye y horroriza" es fundamental para contrarrestar "el orden y la repetición [que] son aledaños a la muerte" (Serres 1982, 127). Pensando en la música, las ideas del Parásito me llevan a pensar en el conocido argumento de Jacques Attali de que los ruidos, al ser espacio de caos y desestabilización de las estructuras sociales, constituyen profecías de futuros cambios culturales. El ruido viene a renovar los fundamentos musicales, y a la luz de una nueva música surgen nuevas formas de ser en el mundo. "El ruido ha sido siempre", insiste aquel autor, "resentido como destrucción, desorden, suciedad, contaminación, agresión contra el código que estructura los mensajes" (Attali 2011, 44). Yo pasaba las tardes entre Serres y Attali, recorriendo la ciudad en busca de una música ruidosa, horrorosa, que rompiera lo cotidiano para crear, al son de lo extraordinario, la posibilidad de un mundo diferente.

\section{I}

Desde el punto de vista de quien se encuentra frente a una mezcladora, hay dos formas de entender el ruido: como un efecto controlado que se genera con fines específicos o como algo inesperado que desborda la expectativa, que trasciende nuestro control transformando nuestros planes. Del feedback indeseado al cable mal soldado, los ruidos accidentales amenazan con deformar nuestras primeras intenciones. Nos horrorizan y nos hacen vulnerables. A diferencia de los estruendos controlados, los productos del descontrol nos conducen a una paradoja: si yo buscaba el ruido como elemento de disrupción, como impacto sobre la escucha acomodada del público, ¿por qué alarmarme ante los sonidos que deforman mis propias expectativas?

Siguiendo con mis lecturas, me encuentro ante las palabras de Michael Hardt y Antonio Negri. Las transformaciones subjetivas, sobre todo aquéllas que conducen a procesos revolucionarios, implican para estos autores un nivel de disrupción sobre nuestra propia identidad constitutiva: "la revolución no es para corazones delicados. Es para monstruos. Uno tiene que desprenderse de lo que es para descubrir lo que puede devenir" (Hardt y Negri 2011, 341) 
- Volviendo a las alucinaciones tempestuosas, me gusta pensar en la música ruidista como un proceso revolucionario que no es para voces delicadas, sino para seres rugientes que rechazan la imposición. Siguiendo con Hardt y Negri, ellos entienden al monstruo shakespereano como personaje decolonial cuyos rugidos amenazan el reinado de su amo. "La cultura de Calibán", nos dicen ellos, "es la cultura de resistencia que vuelve las armas de la dominación colonial contra esta misma" (Hardt \& Negri 2011, 111). Volviendo al escenario, cabe preguntarnos en qué sentido podríamos entender nuestros rugidos como formas de resistencia, hasta dónde estaríamos dispuestos a llegar para que nuestro monstruo se libere del amarre de Próspero.

Hacia las últimas décadas del siglo pasado, hay quienes pensaron que la música ruidista era sintomática de un cambio cultural que preparaba a la humanidad para un nuevo milenio. Una peculiar sensibilidad estaba emergiendo, entre la consolidación de un mercado transnacional y la comercialización de las primeras computadoras personales. Los gritos de Masonna, los circuitos analógicos de Merzbow, eran en el fondo la expresión de un proyecto de humanidad que, aliado con la máquina, distorsionaba las promesas modernistas. Hoy, ya entrados en el siglo XXI, ¿qué tendríamos que decir al respecto?

\section{IV}

El noise es un tipo de música que nació en la circulación y el intercambio internacionales. No en el mercado neoliberal, sino en un circuito alternativo que comenzara con las redes de correo postal, con los conciertos independientes, con los sellos discográficos que reproducen la cultura fanzinera. Hoy en día, con la expansión del Internet y del complejo general de medios digitales, el intercambio transnacional se ha facilitado exponencialmente, situación que la música ruidista ha sabido aprovechar para fortalecer sus propias redes de mercado, sosteniéndose en el filo que une y separa a culturas diversas.

A este respecto, David Novak plantea que "los filos marcan las fronteras del espacio vacío, pero también representan los espacios de transformación donde surgen nuevas posibilidades" (Novak 2013, 19). Si el noise es una música que surge en el filo intercultural, podría ser pensado como una zona donde se generan nuevas posibilidades de encuentro con el otro, de intercam- 
bio no mediado, de creación de circuitos artísticos alternativos que rechacen los filtros y modos de producción de la industria capitalista.

Es verdad que en la actualidad el tema de la circulación cultural, de la globalización y el intercambio no mediado resulta cada vez más complicado: el internet va generando nuevas formas de mediación mientras la autogestión se vuelve cada vez más asequible; sobre los nuevos monopolios de Facebook y Google se erigen nuevos modos de autonomía delimitada, al mismo tiempo que el dólar y el inglés, al expandirse por el mundo, establecen un sistema mercantil de tal totalidad que vuelve absurdo el concepto de diferencia; la colonia neoliberal somete a todo aquel que se opone a los designios de Próspero, pero el rugido de Calibán sigue dando muestras de que es posible, incluso en esta mina de contradicciones, interferir con los planes del mago.

Bajo el estruendo de la ciudad, más allá de la pureza que los sistemas de alta fidelidad ofrecen a los oídos, sigue generándose un ruidismo que se resiste a incorporarse del todo a los modos capitalistas. Ocupando los rincones libertarios del internet -los archivos digitales libres, las redes sociales alternativas-, intercambiando bajo un sistema económico que no se basa en la explotación, en la centralización ni en la privatización de los recursos comunes, siguen emergiendo colectivos, sellos independientes, festivales autogestivos y conciertos de noise en los que prima el jadeo de la bestia.

Hasta dónde puede llegar un mercado alternativo tan limitado y minoritario es difícil saberlo, pero no por ello es menor la prueba de que es posible, en los diversos filos que atraviesan nuestra cultura, abrir espacios de resistencia a la industria musical.

Paso mis manos sobre mi garganta cansada, veo a cinco tipos tirados en el piso sintiendo la vibración que el subwoofer genera. En una esquina tres chicas se balancean, sintiendo las vibraciones mientras exploran el espacio en busca de batimentos, errores de fase, zonas de ensordecimiento que las lleven a descubrir que todo aquel entramado de sensaciones no es más que el resultado de un choque de potencias. No una suma de señales, sino un efecto de resonancia que eleva unos sonidos a la potencia de los otros, extendién- 
dose sobre un espacio cuyas características físicas determinan el resultado sonoro. Las paredes reciben el impacto de las bocinas, pero al mismo tiempo producen el impacto específico que sólo en ellas puede detonarse. De manera similar, el cuerpo de las personas determina también la resonancia sonora: las manos vibran a cierta frecuencia mientras en el pecho son otros armónicos los que destacan, y la cabeza se confunde entre lo que las cócleas perciben y la resonancia que se genera en los distintos huesos del cráneo. El recinto es, visto de ese modo, una escala superior del recinto personal que nuestro propio cuerpo constituye; ambos son escalas de un espacio-mundo que se construye de vibraciones generadas por su propia corporalidad.

Paul Hegarty, autor del conocido ensayo sobre Música/ruido, nos dice que "la música puede organizar nuestros cuerpos y mantener nuestras mentes en orden" $(2007,11)$. Desde esta perspectiva, el ruido puede ser pensado como elemento desorganizador de los cuerpos vibrantes y desordenador de las mentes contemplativas; más aun, puede ser éste concebido como desarticulador de las fronteras que dividen mentes y cuerpos, articulador de un todo resonador que es un cuerpo pensante. Pues los cuerpos, al entregarse a las sensaciones del torrente sonoro, son capaces de imaginar un mundo diferente: uno en el que la escucha se propaga por todos nuestros miembros, en el que todas nuestras neuronas se conectan en una misma sinapsis. No es casualidad, por lo tanto, que en un concierto de noise sea común que la desarticulación de los cuerpos se manifieste de múltiples maneras: si en otros escenarios son frecuentes las orejas perforadas, en la escena noisera los tatuajes, los peircings y el maquillaje se despliegan por todo el territorio corporal, al tiempo que la sexualidad se desenvuelve en un terreno queer en el que el "monstruo" se conduce con bastante soltura. Lo que se busca en estas líneas no es generar estereotipos, sino observar una práctica reiterada en la que el cuerpo se libera de ciertas ataduras, expandiendo el potencial multidimensional de la audición a la membrana celular de todo nuestro yo.

Si el oído ha de ser un órgano desarticulador del cuerpo organizado, si el cuerpo des-organizado ha de ser un punto de ruptura con el modo convencional de habitar nuestro mundo, las ideas parasitarias de Serres vienen a confirmarse en el grito gutural. "La escucha es nuestra apertura heroica a lo problemático y lo difuso; otros receptores sirven para garantizarnos un orden, y en caso de que no otorguen o reciban dicho orden se clausuran de manera inmediata. Ningún otro sentido da cuenta de que que estamos rodeados y al mismo tiempo llenos de fluctuación" (Serres 1982, 127). Pero ¿a qué se refiere este filósofo al hablar de fluctuación que llena nuestra escucha, y cómo habría 
de entenderse esta fluctuación en un fenómeno en el que es el cuerpo entero el que resuena? Quizás ésta sea una cuestión que no se puede resolver únicamente a través de la mente, haciendo necesario un pensar desde el cuerpo que se entrega sin reservas al torrente ruidista.

\section{VI}

Si me hubieran preguntado lo que estaba pensando, si me hubieran cuestionado sobre lo que sentía exactamente en aquellos momentos, no habría sido capaz de expresar una respuesta. Se trataba simplemente de un flujo de excitación que recorría mi cuerpo apoderándose de mi mente. No había tiempo cuantificable ni ideas estructurales que limitaran nuestro grito. Solamente un deseo incontrolable, erótica pulsión que no pasaba por la razón ni por los límites orgánicos de nuestro cuerpo vibrante.

Del amor aristotélico al $m u$ de los budistas, el ser humano ha requerido puntos de sublimación en los que el todo se confunde con la nada. Estos momentos desestructuran la realidad imperante, haciendo de los problemas humanos toscos alejamientos de un estado de plenitud al que podríamos llegar si dejáramos de controlar y nos dejáramos arrastrar sin resistencias por la vida. Este estado es definido por Deleuze y Guattari como un "abrir el cuerpo a conexiones que suponen todo un agenciamiento, circuitos, conjunciones, niveles y umbrales, pasos y distribuciones de intensidad, territorios y desterritorializaciones" $(2004,164)$. Una mera fluctuación, experimentación inmediata, irresoluble, no racionalizable, de un deseo vitalicio cuya única intención es hacernos conscientes de que estamos, simple y llanamente, vivos.

Precisamente es esa la sensación que mejor describiría nuestro grito ruidista: un estar abiertos, dispuestos a que el deseo fluya sin limitarse a las estructuras del orden musical. Contra un "fenómeno de acumulación, de coagulación, de sedimentación que le impone formas, funciones, uniones, organizaciones dominantes y jerarquizadas, transcendencias organizadas para extraer de él un trabajo útil" (Deleuze \& Guattari 2004, 164), nuestro ruido constituía un continuum de intensidades como el que los filósofos franceses denominan cuerpo sin órganos. Una escucha expandida, un estar a la escucha -para retomar la perspectiva del también filósofo francés Jean Luc Nancy (2007)- y hacernos 
escuchar por las personas cuyos cuerpos resonaban al encuentro sonoro con los nuestros.

Quizás en eso consista el monstruoso devenir del que nos hablan Hardt y Negri; tal vez la pérdida de identidad no sea, como algunos podrían proferir, una pérdida de subjetividad ni un proceso de anulación de las diferencias culturales; tal vez se trate, muy en cambio, de la posibilidad de imaginar una nueva identidad en la que la vida no se vea sometida por los valores patriarcales, colonialistas, bélicos y capitalistas que marcan la historia de la insatisfacción humana. Quizás hablemos de un estado de plenitud en el que nuestros monstruos se reconcilian con el monstruo del otro, dejando que el animal conviva, sin ser reprimido, con el ser civilizado, social y cultural cuya característica más humana, la que más lo distingue de otras formas de vida, es su capacidad de desear, de compartir, de convertir en realidad sus deseos.

\section{VII}

Hay quienes insisten en que la música ruidista ha perdido su potencial disruptivo. Hay incluso quienes piensan que el arte en general es hoy en día incapaz de generar rupturas culturales, de remover las estructuras sociales para crear nuevas formas de percibir, tanto individual como socialmente, nuestro mundo. No conforme con tales consideraciones, tomo nuevamente el micrófono, siento la presencia del otro sin necesidad de mirarlo, y me sumerjo nuevamente en el rugido.

Pero por la noche, cuando las luces se han apagado, compruebo con decepción que la ciudad sigue siendo la misma. Igual de contaminada, igual de sostenida por las diversas capas de explotación de las que depende el sistema capitalista, me mira la ciudad con ojos de escepticismo. ¿En qué sueño estuve sumergido? Mientras el tiempo se detuvo en mi éxtasis ruidista, cada luz y cada cable requirió del trabajo de millones de ciudadanos; mientras yo me sublimaba en mi flujo de deseos, el tiempo afuera seguía corriendo y no habían cuerpos que resonaran más allá de las limitadas paredes de mi sueño.

"La realidad está hecha de la misma materia que nuestros sueños", dijo Próspero tras haber recuperado su trono. ¿Qué habría pensado Calibán, para quien el sueño y la realidad eran un mismo continuo de trabajos forzados? 
Seguramente habría rugido, y en su rugir habría proferido maldiciones resentidas contra las palabras irónicas del amo. Así las cosas, sigo caminando por las ruidosas calles de México, confundido por el contraste del mundo real respecto al sueño liberador de un grito ahora lejano.

De pronto, mientras bajo por las escaleras del metro, escucho a una señora canturrear como canturreara el niño en la parábola deleuze-guattariana del ritornelo (Deleuze \& Guattari 2004, 317) . Al igual que aquel infante que con su canto trazara su territorio, la señora generaba con su voz un espacio de estabilidad en donde todo parecía tranquilo. Soñaba mientras cantaba, y mientras tanto trapeaba las escaleras del lugar. Eran las doce de la noche y la mujer parecía cansada, después de una jornada, seguramente larga, limpiando las pisadas de millones de transeúntes que pasaron de largo sin siquiera mirarla: pisadas superpuestas de caminantes anónimos, miradas invidentes de fantasmas invisibles que cruzan el metro a lo largo de los días. Pero a esas horas de la noche la multitud se había extinguido, y el caturreo de la señora resonaba en todo el recinto.

"Buenas noches", dije yo, a lo que ella respondió con una sonrisa. No interrumpió su canturreo; no dejó de trapear, pero tampoco de trazar el territorio que la protegía del cansancio y la soledad del metro nocturno. Es entonces cuando entendí que su historia se conectaba con la historia de mi ruido. Como si volviera a tomar el micrófono, como si estuviera otra vez en el escenario, me animé a acompañar el canto de ella con un tímido tarareo que destruyó la distancia entre nosotros. Fuimos habitantes, al menos por un momento, de un mismo territorio que desbordaba nuestro cansancio y afirmaba al mismo tiempo nuestra unión y nuestra diferencia. Éramos distintos: ella estaba trabajando y yo volvía de tocar, ella estaba en su lugar mientras que yo veía aquel espacio como mera zona de tránsito, pero éramos también entes canturreantes que compartíamos un sueño transitorio. Aquel pacto de complicidad fue bastante similar al que tuviera horas antes con mi amigo rugiente, y nuestro canto desafinado era igual de ruidoso que los gritos desorbitados del concierto ruidista.

¿Dónde reside el potencial revolucionario de un momento como aquél? Tal vez no en generar, como a veces quisiéramos, una acción que revierta los excesos capitalistas, pero sí en comprobar que ni la explotación, ni la alienación ni el trabajo asalariado constituyen la totalidad de lo que somos. Pese a los múltiples estados de opresión que la mayoría de las personas recibimos en nuestro día, existen puntos de fuga en los que nuestro cuerpo se reinventa, en 
los que el deseo fluye libre a través de nuestra escucha, en los que el mercado capitalista cede su lugar al intercambio no mediado o al gesto solidario de un transeúnte canturreante.

Si bien todas las formas de expresión humana tienen sus momentos de fuga y resistencia (la señora del metro es el mejor ejemplo de ello), la música ruidista es una práctica particularmente propicia para que el monstruo se desate liberándose del mago. Quizás por eso me gusta imaginar, cada vez que tomo el micrófono, que construyo con mis gritos un mundo más monstruoso: más abierto a los sentidos, más propicio para crear circuitos alternativos de mercado, más dispuesto a compartir ese gesto atávico, canturreo milenario que es nuestro rugido.

\section{Referencias}

Attali, Jacques. (1977) 2011. Ruidos: Ensayo sobre la economía política de la música. Ed. al cuidado de Federíco Álvarez. México: Siglo XXI

Deleuze, Gilles \& Félix Guattari. (1980) 2004. Mil mesetas: Capitalismo y esquizofrenia. Traducción de José Vázquez Pérez. Valencia: Pre-Textos

Hardt, Michael \& Antonio Negri. 2011. Commonwealth: El proyecto de una revolución del común. Traducción de Raúl Sánchez Cedillo. Madrid: Akal

Hegarty, Paul. 2007. Noise/Music: A history. New York: Bloomsbury

Nancy, Jean-Luc. 2007. A la escucha. Trad., Horacio Pons. Buenos Aires: Amorrortu

Novak, David. 2013. Japanoise Music at the edge of circulation. Durham, NC: Duke University

Serres, Michel. 1982. The Parasite. Translated by Lawrence R. Schehr. Baltimore: John Hopkins University 